Article

\title{
1,4-Disubstituted Thiosemicarbazide Derivatives are Potent Inhibitors of Toxoplasma gondii Proliferation
}

\author{
Katarzyna Dzitko ${ }^{1, *}$, Agata Paneth ${ }^{2,3}$, Tomasz Plech ${ }^{2}$, Jakub Pawelczyk ${ }^{4}$, Paweł Stączek ${ }^{5}$, \\ Joanna Stefańska ${ }^{6}$ and Piotr Paneth ${ }^{3}$
}

1 Department of Immunoparasitology, University of Lodz, Banacha 12/16, 90-237 Lodz, Poland

2 Department of Organic Chemistry, Medical University, Chodźki 4a, 20-093 Lublin, Poland;

E-Mails: agata.siwek@umlub.pl (A.P.); tomasz.plech@umlub.pl (T.P.)

3 Institute of Applied Radiation Chemistry, Technical University of Lodz, Zeromskiego 116, 90-924

Lodz, Poland; E-Mail: piotr.paneth@p.lodz.pl

4 Institute for Medical Biology of the Polish Academy of Sciences, Lodowa 106, 93-232 Łódź, Poland;

E-Mail: jpawelczyk@cbm.pan.pl

5 Department of Genetics of Microorganisms, University of Lodz, Banacha 12/16, 90-237 Lodz, Poland; E-Mail: pstaczek@biol.uni.lodz.pl

6 Department of Pharmaceutical Microbiology, Medical University of Warsaw, Oczki 3, 02-007

Warszawa, Poland; E-Mail: jstefanska@wum.edu.pl

* Author to whom correspondence should be addressed; E-Mail: dzika@biol.uni.lodz.pl;

Tel.: +48-426-354-355; Fax: +48-426-655-818.

Received: 11 June 2014; in revised form: 27 June 2014 / Accepted: 27 June 2014 /

Published: 9 July 2014

\begin{abstract}
A series of 4-arylthiosemicarbazides substituted at the N1 position with a 5-membered heteroaryl ring was synthesized and evaluated in vitro for $T$. gondii inhibition proliferation and host cell cytotoxicity. At non-toxic concentrations for the host cells all studied compounds displayed excellent anti-parasitic effects when compared to sulfadiazine, indicating a high selectivity of their anti- $T$. gondii activity. The differences in bioactivity investigated by DFT calculations suggest that the inhibitory activity of 4-arylthiosemicarbazides towards T. gondii proliferation is connected with the electronic structure of the molecule. Further, these compounds were tested as potential antibacterial agents. No growth-inhibiting effect on any of the test microorganisms was observed for all the compounds, even at high concentrations.
\end{abstract}


Keywords: thiosemicarbazide derivatives; anti-Toxoplasma gondii activity; antibacterial activity; bacterial topoisomerases; toxicity; docking studies; DFT calculations

\section{Introduction}

Toxoplasma gondii ( $T$. gondii) is a worldwide distributed protozoan responsible for toxoplasmosis, one of the most prevalent parasitic infections in humans [1,2]. Typically, $T$. gondii infection in immunocompetent hosts is minor, self-limiting, and the parasite becomes dormant. However, it can have serious effects on immunocompromised individuals, such as HIV-AIDS positive, cancer or organ transplant human patients [2,3]. Under such conditions, T. gondii can result in life-threatening toxoplasmosis with Toxoplasma encephalitis and other complications (i.a. necrotic lesions within the central nervous system or retinochoroiditis) [4,5]. Moreover, women infected with T. gondii for the first time during pregnancy will pass the parasite on to the fetus. The estimated incidence of congenital toxoplasmosis in Poland was compatible with incidences ( 1 to 10 per 10,000 live births) reported in other European countries, in the United States, or in Japan. Congenital T. gondii infection may result in serious neurological and ophthalmic damage to the fetus or even, especially in the first three months of the pregnancy, spontaneous abortion. Furthermore, reactivation of undiagnosed congenital toxoplasmosis can lead to ocular toxoplasmosis later in life, in many cases causing blindness [6-8].

In spite of the severe consequences of toxoplasmosis, the therapy for this disease has not changed in the last 20 years. The current treatment involves the use of synergistic combinations of pyrimethamine, which inhibits the enzymatic activity of dihydrofolate reductase, and sulfonamides such as trimethoprimsulfamethoxazole or sulfadiazine, whose target is dihydropteroate synthetase, supplemented with folinic acid $[9,10]$. The efficacy of this regime is limited, requiring the administration of relatively large amounts of drugs. Side effects include hypersensitivity, haematological toxicity, teratogenicity, allergic reactions, bone marrow suppression, and the development of resistance [11-15]. Furthermore, this treatment is not effective in eliminating the parasite located in the central nervous system [16,17]. An alternative is pyrimethamine in conjunction with clindamycin, spiramycin or atovaquone, but these drugs each possess their own limitations [8-20]. Thus, limited efficacy and side effects of existing drugs together with severe damage caused by $T$. gondii infection clearly indicates the need for development of new non-toxic, well-tolerated, and more efficacious therapeutic agents for controlling and curing toxoplasmosis.

Recently, Liesen et al. [21] have documented for the first time the anti- $T$. gondii activity of thiosemicarbazide-based compounds. According to the biological results, the tested compounds showed better $\mathrm{LD}_{50}$ values for both infected cells and intracellular parasites than the standard drugs sulfadiazine and hydroxyurea (see Figure 1). Since that time, no further reports have appeared in the literature describing the action thiosemicarbazides against $T$. gondii. Inspired by those results, efforts have been made by our research group to expand these initial findings with further details on anti- $T$. gondii activity of thiosemicarbazides. Herein, we present the outcomes of these investigations, as well as the results of subsequent DFT calculations, which allowed us to suggest that inhibitory activity of 4-arylthiosemicarbazides towards $T$. gondii proliferation is connected with the electronic 
structure of the molecule. In further studies, antibacterial activity of title thiosemicarbazide derivatives and inhibitory potency of one selected compound against bacterial type IIA topoisomerases are presented.

Figure 1. Left: Structures of 4-aryl-1-(4-methyl-1H-imidazole-5-yl)carbonylthiosemicarbazides with more potent anti-Toxoplasma gondii activity than the standard drugs sulfadiazine and hydroxyurea [21]; and right: Structures of title 4-aryl-1-hetarylcarbonylthiosemicarbazides.

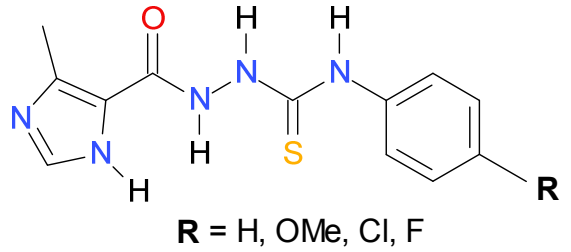

$\mathbf{R}=\mathrm{H}, \mathrm{OMe}, \mathrm{Cl}, \mathrm{F}$

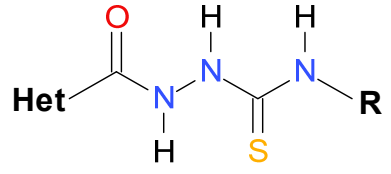

Het $=$ five-membered heterocyclic ring; $\mathbf{R}=$ aryl, alkyl

\section{Results and Discussion}

\subsection{Chemistry}

As mentioned in the Introduction, recently Liesen et al. [21] documented for the first time the anti-Toxoplasma gondii activity of four 4-arylthiosemicarbazides with an imidazole ring at the N1 position (Figure 1). All studied compounds had a range of $\mathrm{LD}_{50}$ values between $0.05-5 \mathrm{mM}$ for infected cells and $0.05-1.5 \mathrm{mM}$ for parasites, indicating a more effective action than the standard drugs sulfadiazine $\left(\mathrm{LC}_{50}>10 \mathrm{mM}\right.$ for infected cells, $\mathrm{LC}_{50}=0.5 \mathrm{mM}$ for intracellular parasites) and hydroxyurea $\left(\mathrm{LC}_{50}>10 \mathrm{mM}\right.$ for infected cells, $\mathrm{LC}_{50}=6 \mathrm{mM}$ for intracellular parasites). According to the SAR analysis results, the electronic nature of the substituents on the phenyl ring of the 4-aryl-1-(4methyl-1H-imidazole-5-yl)carbonylthiosemicarbazides seemed to have a low influence on bioactivity, thus indicating the dominant role of the imidazole moiety for modulating the bioactivity of the studied compounds. The promising bioassay results inspired us to design a series of 4-arylthiosemicarbazides with thiadiazole, thiophene or furan rings at the N1 position. Based on the results presented by Liesen et al. [21] we expected that the replacement of the imidazole core in 4-aryl-1-(4-methyl-1H-imidazole5-yl)carbonylthiosemicarbazide with a similarly sized five-membered heteroaryl ring would result in compounds with a comparable bioactivity profile. The designed thiosemicarbazides presented structures similar to those proposed by Liesen et al. [21], with sulphur and oxygen atoms at $\mathrm{C}(=\mathrm{O}) \mathrm{NHNHC}(=\mathrm{S})$ core on the same side (Figure 2, left) or on the opposite side of the molecule (Figure 2, right), as confirmed by Amber calculations [22].

Subsequently, these compounds were synthesized and Scheme 1 shows the synthetic route employed for their preparation. As can be seen, a simple synthesis was carried out, starting from the commercially available carboxylic acid hydrazides and the appropriate isothiocyanates, in ethanolic medium. At the end of the reaction, the isolated thiosemicarbazide derivatives were obtained as colourless solids. This procedure was adapted from an article previously reported by Plech et al. [23] and gave us satisfactory yields. 
Figure 2. Structures of representative 4-aryl-1-(4-methyl-1H-imidazole-5yl)carbonylthiosemicarbazides [21] with sulphur and oxygen atoms at $\mathrm{C}(=\mathrm{O}) \mathrm{NHNHC}(=\mathrm{S})$ core on the same side (left) or on the opposite side of the molecule (right).

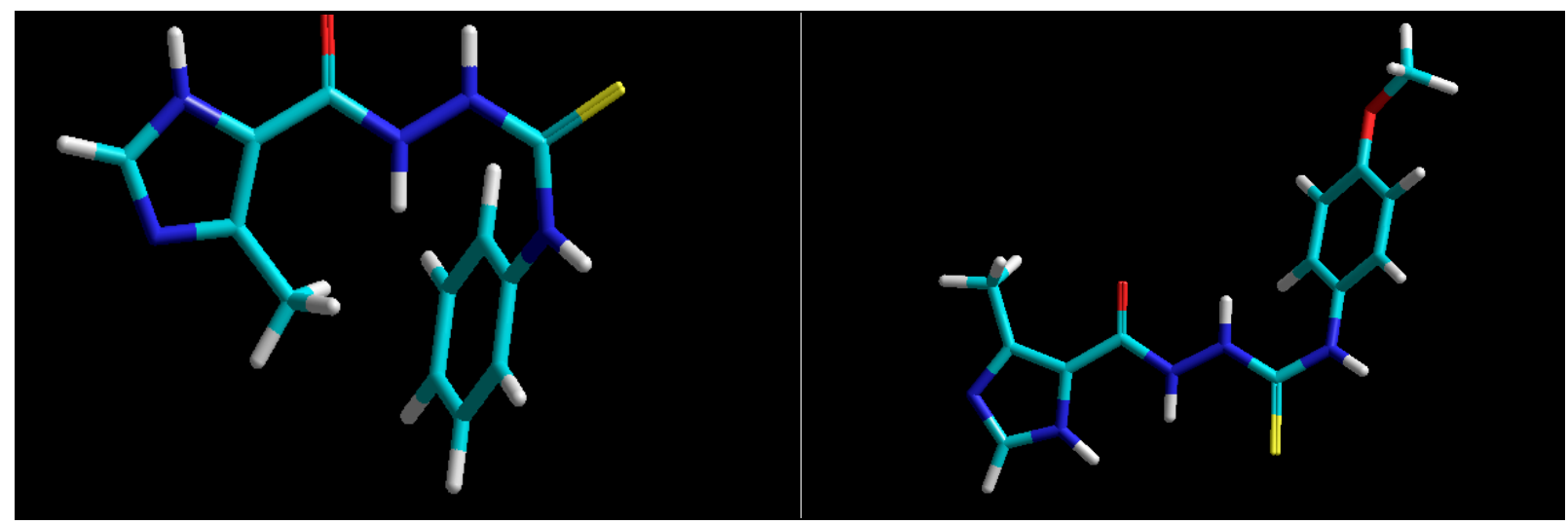

Scheme 1. Synthetic route for 1,4-disubstituted thiosemicarbazides (series 1-3).

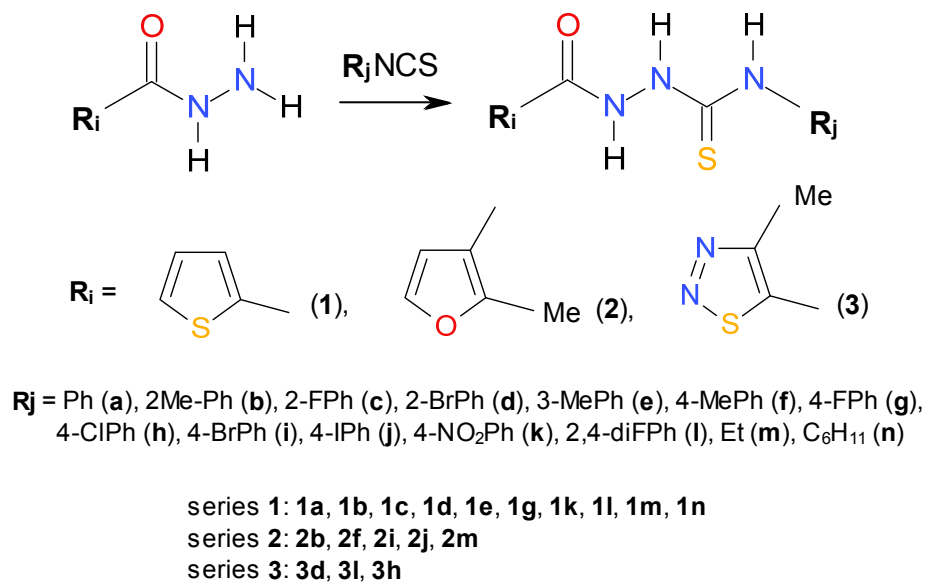

\subsection{In Vitro Anti-Toxoplasma gondii Activity of the Title Compounds}

In the next step of our studies, the prepared 1,4-disubstituted thiosemicarbazides (series 1-3) were used to assess the inhibition of $T$. gondii growth in vitro. For this purpose, intracellular parasites (tachyzoites) of RH strain were incubated with different concentrations of the thiosemicarbazides ranging from 1 to $100 \mu \mathrm{g} / \mathrm{mL}$. Inhibition of the parasite growth was monitored by measuring the specific incorporation of $\left[{ }^{3} \mathrm{H}\right]$ uracil in the parasite's nucleic acids. Unfortunately, among the 15 compounds tested, derivatives $\mathbf{1 a}-\mathbf{1 e}, \mathbf{1 k}, \mathbf{1}, \mathbf{2} \mathbf{f}, \mathbf{2} \mathbf{i}, \mathbf{2} \mathbf{j}$, and $\mathbf{3 h}$ were insoluble under the protocol conditions and, consequently, they were eliminated from further experiments. The percentages of the parasite growth inhibition in L929 cells by the remaining compounds $\mathbf{1 g}, \mathbf{2 b}, \mathbf{3 d}, \mathbf{3 l}$ and the control drug-sulfadiazine as well as $\mathrm{IC}_{50}$ values are shown in Table 1. 
Table 1. Effect of studied compounds on the intensity of $T$. gondii proliferation (\%) in the L929 host cells.

\begin{tabular}{|c|c|c|c|c|c|c|c|}
\hline \multirow[b]{2}{*}{ Cmpd. No. } & \multirow{2}{*}{$\begin{array}{l}\text { Assay: } \\
\text { A. }\left[{ }^{3} \mathrm{H}\right] \text { Uracil Incorporation } \\
\text { B. qRT-PCR }\end{array}$} & \multicolumn{5}{|c|}{ Concentration $[\mu \mathrm{g} / \mathrm{mL}]$} & \multirow[b]{2}{*}{$\mathrm{IC}_{50}[\mu \mathrm{g} / \mathrm{mL}]$} \\
\hline & & 100 & $\mathbf{5 0}$ & 10 & 5 & 1 & \\
\hline \multirow{2}{*}{$1 g$} & A. & $\mathrm{nt}$ & $12.62 \pm 4.78 *$ & $44.71 \pm 16.60 *$ & $74.94 \pm 7.00 *$ & $96.14 \pm 14.54$ & 33.17 \\
\hline & B. & $\mathrm{nt}$ & $5.00 \pm 2.56 *$ & $61.01 \pm 11.23 *$ & $\mathrm{nt}$ & $\mathrm{nt}$ & $\mathrm{nt}$ \\
\hline \multirow{2}{*}{$2 \mathbf{b}$} & A. & $8.10 \pm 2.78 *$ & $58.78 \pm 11.49^{*}$ & $112.25 \pm 22.91 *$ & $107.95 \pm 24.88$ & $98.24 \pm 23.83$ & 59.00 \\
\hline & B. & $7.29 \pm 1.56 *$ & $41.37 \pm 9.98 *$ & $\mathrm{nt}$ & $\mathrm{nt}$ & $\mathrm{nt}$ & $\mathrm{nt}$ \\
\hline \multirow{2}{*}{ 3d } & A. & $36.52 \pm 5.16^{*}$ & $63.82 \pm 5.32 *$ & $83.84 \pm 19.01$ & $84.64 \pm 15.68$ & $90.03 \pm 14.61$ & 74.93 \\
\hline & B. & $25.56 \pm 6.32 *$ & $75.13 \pm 10.10 *$ & $\mathrm{nt}$ & $\mathrm{nt}$ & $\mathrm{nt}$ & $\mathrm{nt}$ \\
\hline \multirow{2}{*}{31} & A. & $37.20 \pm 7.47 *$ & $88.34 \pm 14.40 *$ & $103.21 \pm 19.27$ & $85.76 \pm 19.71$ & $84.59 \pm 16.61$ & 92.28 \\
\hline & B. & $14.08 \pm 3.35 *$ & $89.32 \pm 15.74 *$ & $\mathrm{nt}$ & $\mathrm{nt}$ & $\mathrm{nt}$ & $\mathrm{nt}$ \\
\hline \multirow{2}{*}{ sulfadiazine } & A. & $71.53 \pm 8,94 *$ & $78.73 \pm 8,29 *$ & $82.14 \pm 11,26$ & $79.18 \pm 6,29 *$ & $90.37 \pm 11,65 *$ & $>500 * *$ \\
\hline & B. & $63.99 \pm 10.58 *$ & $\mathrm{nt}$ & $\mathrm{nt}$ & nt & $\mathrm{nt}$ & $\mathrm{nt}$ \\
\hline \multirow{2}{*}{$2 m$} & A. & $57.59 \pm 15.02 *$ & $66.49 \pm 11.38 *$ & $60.61 \pm 9.56 *$ & $75.74 \pm 14.62$ & $98.00 \pm 19.53$ & 191.04 \\
\hline & B. & $53.03 \pm 9.87 *$ & $51.03 \pm 7.02 *$ & $\mathrm{nt}$ & nt & $\mathrm{nt}$ & $\mathrm{nt}$ \\
\hline
\end{tabular}

nt: Not tested, $* p<0.05$; to calculate the intensity of $T$. gondii proliferation compared to the untreated blank, the Equation was used: proliferation $(\%)=[100 \times$ sample $\mathrm{OD}_{570}$ (the mean value of the measured optical density of the $1-100 \mu \mathrm{g} / \mathrm{mL}$ compounds of the test samples / blank $\mathrm{OD}_{570}$. (the mean value of the measured optical density of the untreated cells) $]. \mathrm{IC}_{50}[\mu \mathrm{g} / \mathrm{mL}]$ : Represents the concentration of tested compounds that was required for $50 \%$ of $T$. gondii proliferation inhibition in vitro. ** Numerous studies have shown that the drug susceptibility for parasites depended on the host cells used. Using as a model, RH strain and human MRC-5 cells [24,25], Vero [26] and HFF [27] as a host normal cells, the $\mathrm{IC}_{50}$ value of sulfadizaine reached from 2.5 to $77 \mu \mathrm{g} / \mathrm{mL}$ compared to human carcinoma HEp-2 and HeLa cells showing $\mathrm{IC}_{50}$ values between $600-700 \mu \mathrm{g} / \mathrm{mL}$ and $>1000 \mu \mathrm{g} / \mathrm{mL}$, respectively [28,29]. 
According to these results, all thiosemicarbazides 19, 2b, 3d, 31 showed significant and reproducible anti-parasitic effects, with the assigned $\mathrm{IC}_{50}$ values 5- to 15 -fold lower than those observed for sulfadiazine $\left(\mathrm{IC}_{50}>500 \mu \mathrm{g} / \mathrm{mL}\right.$ ). Among them, a derivative with the thiophene ring of $\mathbf{1 g}$ was found to be the most potent anti-T. gondii agent, with an $\mathrm{IC}_{50}$ of $33.17 \mu \mathrm{g} / \mathrm{mL}$. When the thiophene scaffold was replaced with a similar in size furan moiety, as exemplified by $\mathbf{2} \mathbf{b}$, or a thiadiazole core, as exemplified by $\mathbf{3 d}, \mathbf{3 1}$, bioactivity was substantially lost. $\mathrm{IC}_{50}$ values determined for 2b, 3d, 3l, however, were still at least 5-fold lower than the values obtained for sulfadiazine (see A in Table 1). High anti-parasitic activity of all selected thiosemicarbazides $\mathbf{1 g}, \mathbf{2 b}, \mathbf{3 d}$, and $\mathbf{3 1}$ was also confirmed using a quantitative real-time PCR (qRT-PCR) assay (B in Table 1).

A preliminary assumption was thus put forward that the presence of both the five-membered hetaryl moiety at N1 position and the aryl moiety at N4 position of thiosemicarbazide core are the key functionalities required for potent anti- $T$. gondii activity of thiosemicarbazide-based compounds, which may be directly linked with the electronic structure of the molecule. In order to verify the preliminary hypothesis, 4-ethyl-1-(thiophen-2-yl)carbonylthiosemicarbazide (1m), 4-cyclohexyl-1(thiophen-2-yl)carbonylthiosemicarbazide (1n), and 4-ethyl-1-(2-methylfuran-3-yl)carbonylthiosemicarbazide (2m) were synthesized and their bioactivity was tested. Unfortunately, derivatives $\mathbf{1 m}$ and $1 \mathrm{n}$ were insoluble under the protocol conditions and, consequently, they were eliminated from further experiments. Indeed, the replacement of the ortho-tolyl ring in $\mathbf{2 b}$ with the ethyl chain as in $\mathbf{2 m}$ resulted in a significant loss of bioactivity $\left(\mathrm{IC}_{50} 59.00 v \mathrm{~s} .191 .04 \mu \mathrm{g} / \mathrm{mL}\right.$, see Table 1 last entry), thereby confirming the validity of the aforementioned assumption. The assumption of the existence of the relationship between the anti- $T$. gondii activity of the studied thiosemicarbazides and their molecular structure was also confirmed based on DFT calculations. Figure 3 illustrates the electrostatic potential mapped on the density surface using the Gaussview program. Neutral fragments are characterized by the green color of the surface. The negative charge is represented by red, while the positive charge is marked in blue. If compound $\mathbf{1 g}$ is excluded from the consideration, the biological activity correlates well with the dipole moment of the molecule. In this series it seems that the activity depends on the bimodal partial negative charge developed on the carbonyl oxygen and another moiety on the same side of the molecule (a sulfur atom in $\mathbf{2 b}$ and $\mathbf{3 d}$ ). Its low value in $\mathbf{3} \mathbf{l}$ and lack in $\mathbf{2 m}$ may be responsible for the lower activity. However, the most active compound $\mathbf{1 g}$ is characterized by the lowest dipole moment. It contains, however, two partial negative charge centers as the series discussed above and an additional such center on the fluorine atom. Comparison of the biological activity of $\mathbf{1 g}$ and $\mathbf{2 m}$ seems to indicate the crucial role of the second negative charge density on the top of the molecule on a moiety other than the carbonyl oxygen. Another observation that comes from the analysis of the presented structures is that the biological activity is pronounced when the methyl group of the five-membered ring is directed away from the carbonyl group. Since the number of compounds studied here is limited, the above observations can be treated as initial suggestions only and will be used as a guide for synthesis of other compounds in further studies.

In order to understand the molecular mechanism by which thiosemicarbazides induce their inhibitory activity towards $T$. gondii, the docking studies were carried out. The knowledge of unique aspects of $T$. gondii biochemistry and physiology has led to the identification of seven enzymes, essential for the survival, growth, replication, or viability of the microorganism, as reasonable targets for anti-Toxoplasma agents. According to the enzymatic studies, purine nucleoside phosphorylase 
(PNP) [30], adenosine kinase [EC.2.7.1.20] [31], dihydrofolate reductase (DHFR) [32,33], calciumdependent protein kinase-1 (TgCDPK1) [34-37], 1-deoxy-D-xylulose-5-phosphate reductoisomerase (DXR) [38-40], enoyl reductase (TgENR) [41] were considered as attractive targets for discovering selective inhibitors to combat infections caused by this protozoan. Inspired by these results, based on the structures deposited in the Protein Data Bank, we analyzed the binding affinity of the title thiosemicarbazides with the active sites of aforementioned enzymes, with the exception of the model of dihydrofolate reductase (DHFR) binding site (PDB ID 4EIL) that retained several pathologies. The docking simulations were performed using the FlexX docking module [42] of the LeadIT environment as implemented in the BioSolveITprogram [43]. The total docking and hide scores of the studied compounds within the active sites of target enzymes together with H-bonds and close hydrophobic interactions are displayed in Table S1 in Supplementary Material. Although no structure-activity relationships (SAR) trends were observed when the docking conformations, the scores, and the interactions between thiosemicarbazide and residues of the binding site were analyzed in detail, all compounds were recognized as potential inhibitors of studied enzymes. To these enzymes, ribonucleotide reductase should also be included since this enzyme was identified as molecular target for anti- $T$. gondii activity of thiosemicarbazones - compounds closely related to thiosemicarbazides [21]. Of course, these above-mentioned proteins are only a very small cross-section of the potential protein targets within $T$. gondii. Evidently, enzymatic studies are necessary to develop our knowledge of the molecular basis of thiosemicarbazide derivatives bioactivity.

Figure 3. The electrostatic potential surfaces and dipole moments of $\mathbf{1 g}, \mathbf{2 b}, \mathbf{2 m}, \mathbf{3 d}$, and $\mathbf{3 1}$.

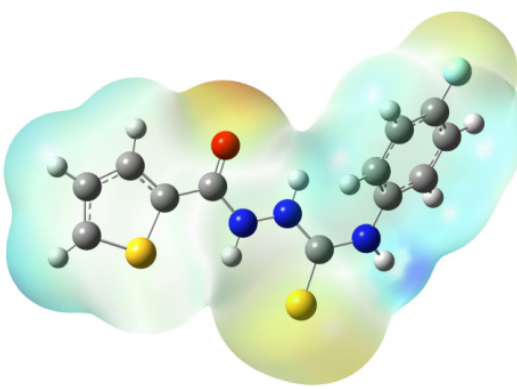

$\operatorname{1g} \mu=1.99 \mathrm{D}$

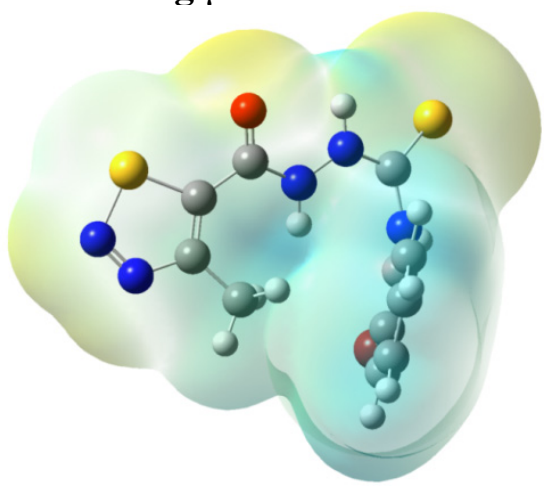

3d $\mu=6.25 \mathrm{D}$

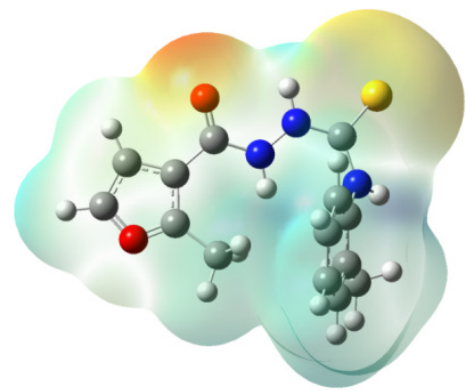

2b $\mu=8.30 \mathrm{D}$

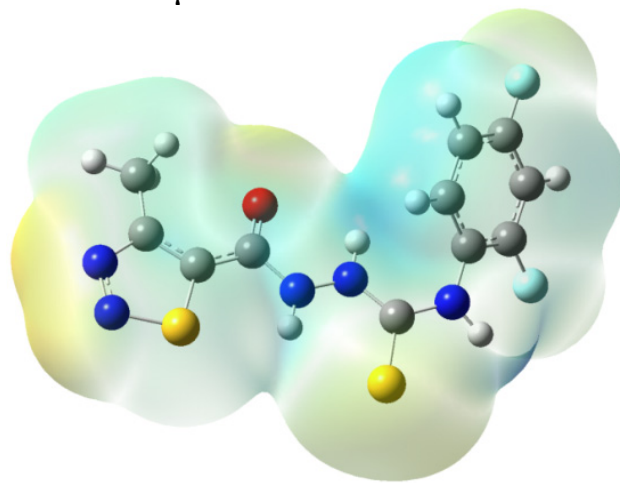

$31 \mu=4.12 \mathrm{D}$

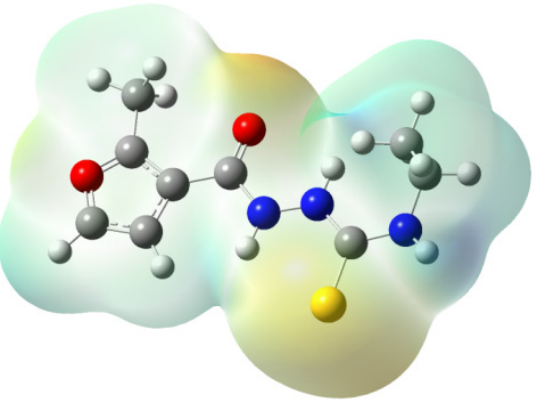

$2 \mathbf{m} \mu=2.95 \mathrm{D}$ 


\subsection{Cytotoxicity of $\mathbf{1 g}, \mathbf{2 b}, \mathbf{2} \mathbf{m}, \mathbf{3 d}$, and $\mathbf{3 1}$ against L929 Cells}

Since all studied compounds appeared to be more potent than control drug sulfadiazine, the assay for the protozoan parasite $T$. gondii has been expanded to include a preliminary study on their in vitro host cell toxicity effects using an MTT assay. From a biological point of view, it is important for the studied compounds to inhibit the parasite growth at a low concentration and at the same time show no or low toxicity effects on host cells. Otherwise, the activity might be just due to the general toxicity, which disqualifies the compound as a drug or lead molecule candidate. Fortunately, from a comparison of the cytotoxicity test $\left(\mathrm{CC}_{30}\right.$, Table 2$)$ results and anti- $T$. gondii activity tests (Table 1$)$, it can be seen clearly that all tested compounds inhibited the parasite growth at non-cytotoxic concentrations in host cells. The morphology of normal cells and the morphology of cells cultured with tested compounds are presented in Figure S1 in Supplementary Material.

Table 2. The viability of L929 cells (in \% of viable L929 cells) in the concentration range of $\mathbf{1 g}, \mathbf{2 b}, \mathbf{2 m}, \mathbf{3 d}$, and $\mathbf{3 l}$ between $1 \mu \mathrm{g} / \mathrm{mL}$ and $500 \mu \mathrm{g} / \mathrm{mL} \pm \mathrm{SD}$.

\begin{tabular}{cccccccc}
\hline Cmpd. & \multicolumn{7}{c}{ Concentration $[\boldsymbol{\mu g} / \mathbf{m L}]$} \\
\cline { 2 - 8 } No. & $\mathbf{5 0 0}$ & $\mathbf{1 0 0}$ & $\mathbf{5 0}$ & $\mathbf{1 0}$ & $\mathbf{5}$ & $\mathbf{1}$ & $\mathbf{C}$ \\
\hline $\mathbf{1 g}$ & $39.76 \pm 5.83 *$ & $67.00 \pm 11.38 *$ & $79.05 \pm 2.89 *$ & $97.32 \pm 4.98$ & $99.51 \pm 5.16$ & $102.52 \pm 2.69$ & 210.04 \\
$\mathbf{2 b}$ & $30.28 \pm 0.86$ & $78.22 \pm 1.61 *$ & $84.54 \pm 1.43 *$ & $91.93 \pm 5.21 *$ & $94.01 \pm 1.78 *$ & $95.27 \pm 9.52$ & 187.51 \\
$\mathbf{3 d}$ & $41.45 \pm 5.16 *$ & $79.53 \pm 5.82 *$ & $90.88 \pm 6.71 *$ & $97.51 \pm 5.98$ & $99.14 \pm 0.82$ & $102.36 \pm 3.89$ & 242.56 \\
$\mathbf{3 1}$ & $48.02 \pm 10.12 *$ & $89.55 \pm 3.44 *$ & $99.04 \pm 10.02 *$ & $95.89 \pm 0.39 *$ & $92.87 \pm 0.23 *$ & $96.54 \pm 0.69$ & 285.52 \\
$\mathbf{2 m}$ & $80.40 \pm 2.74 *$ & $92.17 \pm 2.31 *$ & $90.49 \pm 2.99 *$ & $94.05 \pm 5.13$ & $94.44 \pm 2.62$ & $104.05 \pm 0.12$ & $>500$ \\
\hline
\end{tabular}

$* p<0.05$; To calculate the reduction of viability compared to the untreated blank the Equation was used: viability $(\%)=100 \times$ sample $\mathrm{OD}_{570}$ (the mean value of the measured optical density of the $1-100 \mu \mathrm{g} / \mathrm{mL}$ compounds of the test samples/blank $\mathrm{OD}_{570}$ ( the mean value of the measured optical density of the untreated cells). $\mathrm{CC}_{30}[\mu \mathrm{g} / \mathrm{mL}]$ - represents the concentration of tested compounds that was required for $30 \%$ proliferation inhibition in vitro. The effect of tested compounds on the cell line L929 (\%) was measured using MTT assay according to the international standards: ISO 10993-5:2009(E).

\subsection{Antibacterial Activity and Inhibitory Potency against Bacterial Type IIA Topoisomerases}

In our resent papers $[23,44]$ we have reported the antibacterial activity of thirty-one 4-arylthiosemicarbazides and found that some of tested compounds were effective against the reference strains of Gram-positive bacterial species and clinical isolates of Staphylococcus aureus with minimal inhibitory concentrations (MICs) in the range of $15.63-62.50 \mu \mathrm{g} / \mathrm{mL}$. In addition, we have also reported two thiosemicarbazide derivatives [45], that is 4-benzoyl-1-(4-methyl-imidazol-5yl)carbonylthiosemicarbazide with $\mathrm{IC}_{50}$ at $90 \mu \mathrm{g} / \mathrm{mL}$ and 4-benzoyl-1-(indol-2-yl)carbonylthiosemicarbazide with $\mathrm{IC}_{50}$ at $14 \mu \mathrm{g} / \mathrm{mL}$, as initial prototypes of a novel class of inhibitors of bacterial topoisomerase IV - the enzyme that is essential for proper chromosome segregation and, consequently, to the survival of prokaryotic cells [46]. It was reasonable to suppose, therefore, that title compounds may also possess antibacterial activity. Thus, in addition to the antitoxoplasmic assays, we also tested antibacterial potency of $\mathbf{1 g}, \mathbf{2 b}$, and $\mathbf{2 m}$ against panel of Gram-positive and Gram-negative bacterial strains. The antibacterial screening for compounds 3d and $\mathbf{3 l}$ was presented in our previous contribution [38] and it was found that both compounds were ineffective against all test 
microorganisms. Unfortunately, no growth-inhibiting effect on both Gram-positive and Gram negative bacterial strains was also observed for compounds $\mathbf{1 g}, \mathbf{2 b}$, and $\mathbf{2 m}$ even at high concentrations. Nevertheless, as the geometry of molecule $1 \mathrm{~g}$ was similar to that of previously reported initial hits [39] (Figure 4), DNA gyrase and topoisomerase IV inhibition tests for $\mathbf{1 g}$ were also conducted. No inhibitory effect, however, was observed against both bacterial enzymes.

Figure 4. Overlay of the structures of known S. aureus topoisomerase IV inhibitor (tubes) [39] and 4-(4-fluorophenyl)-1-(thiophen-2-yl)carbonylthiosemicarbazide 1g (balls and sticks).

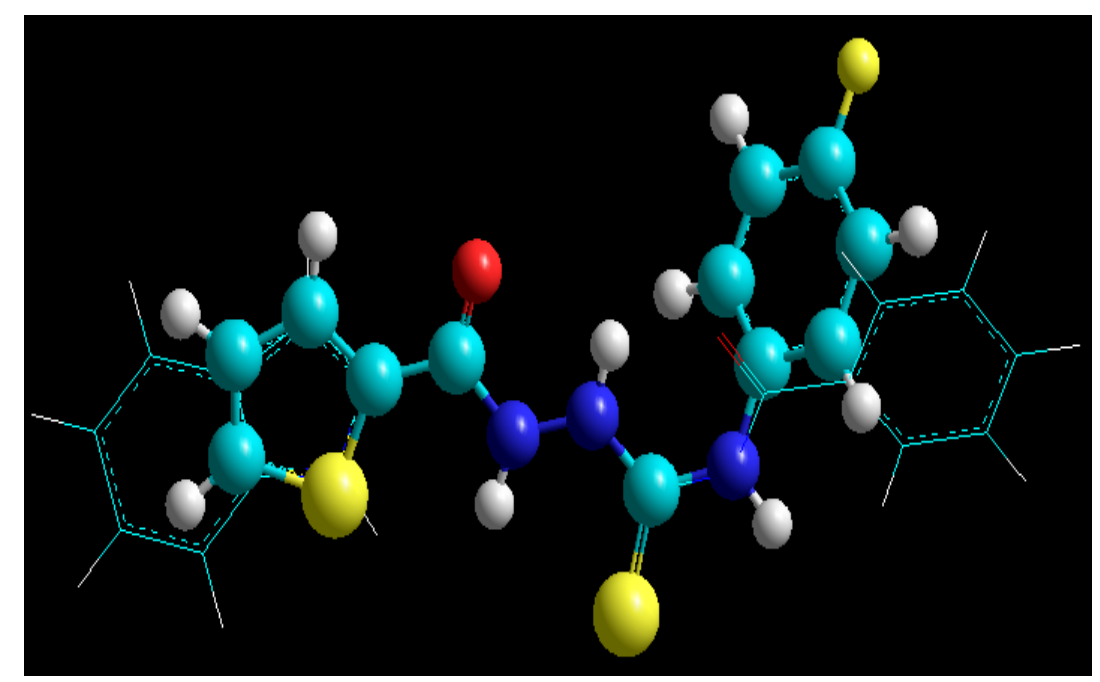

\section{Experimental}

\subsection{General Information}

All commercial reactants and solvents were purchased from either Sigma-Aldrich ((St. Louis, MS, USA) or Lancaster ((Ward Hill, NY, USA) with the highest purity and used without further purification. Melting points were determined on a Fischer-Johns block and are uncorrected. Elemental analyses were performed by a AMZ-CHX elemental analyzer. IR spectra were recorded in $\mathrm{KBr}$ using a Specord IR-75 spectrophotometer. ${ }^{1} \mathrm{H}-\mathrm{NMR}$ spectra were recorded on a Bruker Avance $(300 \mathrm{MHz})$. Analytical thin layer chromatography (TLC) was performed with Merc $60 \mathrm{~F}_{254}$ silica gel plates and visualized by UV irradiation $(254 \mathrm{~nm})$.

\subsection{Chemistry: General Procedure for Synthesis of 1-Substituted-4-arylthiosemicarbazides}

A solution of $0.01 \mathrm{~mol}$ of carboxylic acid hydrazide and an equimolar amount of the appropriate isothiocyanate in anhydrous EtOH $(25 \mathrm{~mL})$ was heated under reflux for $30 \mathrm{~min}$. Next, the solution was cooled and the solid formed was filtered off, washed with diethyl ether, dried, and crystallized from EtOH. Physicochemical characterizations of 1a, 1c, 1d, 1g, 1k, 1l, 1m, 1n, 2b, 2f, 2i, 3d, 3h, and $3 \mathbf{l}$ has been presented previously [38,47-52]. The structures of compounds $\mathbf{1 b}$ (CAS number 891059-78-2) and 1e (CAS number 903081-57-2) are known, however, there is no reference reporting their use or preparation or physico-chemical characterization, therefore their data have been included in this manuscript. 
4-(2-Methylphenyl)-1-(thiophen-2-yl)carbonylthiosemicarbazide (1b). Yield: 94\%. Mp: 155-157 ${ }^{\circ} \mathrm{C}$. IR $\left(\mathrm{v}, \mathrm{cm}^{-1}\right)$ 3354, 3337, $3308(\mathrm{NH}), 3084,1601,1586,1527,1485,730$ (Ar-H), 2922, 1349 (Aliph.), $1664(\mathrm{C}=\mathrm{O}), 1245(\mathrm{C}=\mathrm{S}), 775(\mathrm{C}-\mathrm{S}) .{ }^{1} \mathrm{H}-\mathrm{NMR}\left(\mathrm{DMSO}_{-} \mathrm{d}_{6}\right) \delta_{\mathrm{H}} 2.19\left(\mathrm{~s}, 3 \mathrm{H}, \mathrm{CH}_{3}\right), 7.10-7.23(\mathrm{~m}, 5 \mathrm{H}$, $\left.4 \times \mathrm{CH}_{\mathrm{ar}} \& \mathrm{CH}_{\text {thiophene }}\right), 7.83-7.86\left(\mathrm{~m}, 2 \mathrm{H}, 2 \times \mathrm{CH}_{\text {thiophene }}\right), 9.62,10.55(2 \mathrm{~s}, 3 \mathrm{H}, 3 \times \mathrm{NH})$. Anal. Calcd for $\mathrm{C}_{13} \mathrm{H}_{13} \mathrm{~N}_{3} \mathrm{OS}_{2}$ (291.39): C, 53.58; H, 4.50; N, 14.42. Found: C, 53.72; H, 4.59; N, 14.66.

4-(3-Methylphenyl)-1-(thiophen-2-yl)carbonylthiosemicarbazide (1e). Yield: 93\%. Mp: 188-190 ${ }^{\circ} \mathrm{C}$. IR $\left(v, \mathrm{~cm}^{-1}\right)$ 3321, $3220(\mathrm{NH})$, 3095, 3047, 1625, 1511, 725 (Ar-H), 2916, 1492, 1365 (Aliph.), 1664 $(\mathrm{C}=\mathrm{O}), 1235(\mathrm{C}=\mathrm{S}), 773(\mathrm{C}-\mathrm{S}) .{ }^{1} \mathrm{H}-\mathrm{NMR}\left(\mathrm{DMSO}_{-} \mathrm{d}_{6}\right) \delta_{\mathrm{H}} 2.29\left(\mathrm{~s}, 3 \mathrm{H}, \mathrm{CH}_{3}\right), 6.96-6.98(\mathrm{~m}, 1 \mathrm{H}$, $\left.\mathrm{CH}_{\text {thiophene }}\right), 7.17-7.29\left(\mathrm{~m}, 4 \mathrm{H}, 2 \times \mathrm{CH}_{\mathrm{ar}}\right), 7.84-7.87$ (m, 2H, $\left.2 \times \mathrm{CH}_{\text {thiophene }}\right), 9.68,9.81,10.53(2 \mathrm{~s}, 3 \mathrm{H}$, $3 \times \mathrm{NH}$ ). Anal. Calcd for $\mathrm{C}_{13} \mathrm{H}_{13} \mathrm{~N}_{3} \mathrm{OS}_{2}$ (291.39): C, 53.58; H, 4.50; N, 14.42. Found: C, 53.53; H, 4.66; $\mathrm{N}, 14.51$.

\subsection{Assay in Vitro for Anti-T. gondii Activity}

\subsubsection{Animals}

Inbred mice were kept under standard laboratory conventional conditions. All experimental procedures were conducted according to guidelines of the 9. Local Ethics Commission for Experiments on Animals in Lodz.

\subsubsection{Parasites}

The tachyzoites of $T$. gondii strain RH - intraspecies type I (ATCC_ Number 50174 ${ }^{\mathrm{TM}}$ ) were maintained through passages on female C57BL/6 $\left(\mathrm{H}-2^{\mathrm{b}}\right)$ and BALB/c $\left(\mathrm{H}-2^{\mathrm{d}}\right)$ mice with genetically determined high and low susceptibility (respectively) to $T$. gondii infection (10-12 weeks old). Tachyzoites washed out from the peritoneum cavity were once expanded in vitro on L929 cells.

\subsubsection{Influence of Thiosemicarbazide Derivatives on T. gondii Proliferation}

L929, $\left(2 \times 10^{4}\right.$ cells/100 $\mu \mathrm{L} /$ well $)$ were grown in complete medium (IMDM) on 96-well plates. After $24 \mathrm{~h}$ incubation, a medium was removed and then $T$. gondii RH tachyzoites, suspended in culture medium supplemented with 1.0, 5.0, 10.0, 50.0 and $100.0 \mu \mathrm{g} / \mathrm{mL}$ 1,4-disubstituted thiosemicarbazides $(\mathbf{1 g}, \mathbf{2 b}, \mathbf{2 m}, \mathbf{3 d}, \mathbf{3 l})$ and as a control-sulfadiazine, were added $\left(2 \times 10^{5}\right.$ tachyzoites $\left./ 200 \mu \mathrm{L} / \mathrm{well}\right)$ to the cell monolayers. After subsequent $48 \mathrm{~h}$ incubation $1 \mu \mathrm{Ci} /$ well of $\left[{ }^{3} \mathrm{H}\right]$ uracil (Moravek Biochemicals Inc., Brea, CA, USA) was applied to each microculture for further 18-20 h. The amount of the isotope incorporated into the parasite nucleic acid pool, corresponding to the parasite growth, was measured by liquid scintillation counting with 1450 Microbeta Plus Liquid Scintillation Counter (Wallac Oy, Turku, Finland). The cpms of host cells alone (below 250/microculture) were subtracted from cpms of T. gondii infected microcultures. 


\subsection{Quantitative Real-Time PCR}

\subsubsection{DNA Extraction}

T. gondii genomic DNA was isolated from the tachyzoites of RH strain with Wizard ${ }^{\circledR} \mathrm{SV}$ Genomic DNA Purification System (Promega, Madison, WI, USA) according to the manufacturer's instruction. The DNA concentration and purity were measured using a NanoPhotometer (Implen, München, Germany), while the integrity of the extracted DNA was tested using an ethidium bromide-stained agarose gel. DNA was used for the detection and quantitation of $T$. gondii in analyzed samples and it was stored at $-20{ }^{\circ} \mathrm{C}$ until use.

\subsubsection{Detection in Infected Cells in the Presence of Tested Compounds}

A quantitative real-time PCR (qRT-PCR) assay, targeting B1 gene [53] was performed to detect and to quantitate $T$. gondii in analyzed samples $(\mathbf{1 g}, \mathbf{2 b}, \mathbf{2} \mathbf{m}, \mathbf{3 d}, \mathbf{3} \mathbf{l}$ and sulphadiazine) according to the modified protocol of Wahab et al. [54]. The forward primer GCATTGCCCGTCCAAACT, the reverse primer AGACTGTACGGAATGGAGACGAA and 5'-Fam-CAACAACTGCTCTAGCG-BHQ-1-3' probe were used. Amplification was carried out on a 7900HT real-time PCR system (Applied Biosystems, Carlsbad, CA, USA). The reaction mixtures $(25 \mu \mathrm{L})$ consisted of $1 x$ TaqMan PCR master mix supplemented with ROX (Applied Biosystems), $300 \mathrm{nM}$ probe, $900 \mathrm{nM}$ of each primer and $2 \mu \mathrm{L}$ of template DNA. For quantification a standard curve was constructed using 10-fold serial dilutions of DNA extracted from a known number of $T$. gondii. The cycling parameters were: $50{ }^{\circ} \mathrm{C}$ for 2 min, initial activation at $95{ }^{\circ} \mathrm{C}$ for $10 \mathrm{~min}$, and 45 two-step cycles of $95{ }^{\circ} \mathrm{C}$ for $15 \mathrm{~s}$ and $60{ }^{\circ} \mathrm{C}$ for $1 \mathrm{~min}$. All samples were analyzed in triplicate.

\subsection{Cytotoxic Assay}

\subsubsection{Cell Culture}

Cell line L929 (ATTC ${ }^{\circledR}$ Catalog No. CCL-1, mouse fibroblasts) was routinely cultured in Iscove's modified Dulbecco medium (IMDM, Cytogen, Princeton, NJ, USA), supplemented with 10\% (v/v) fetal bovine serum (FBS, Sigma), plus $2 \mathrm{mM} \mathrm{L-glutamine} \mathrm{(Sigma),} 100.0 \mathrm{U} / \mathrm{mL}$ penicillin (Sigma), $100.0 \mu \mathrm{g} / \mathrm{mL}$ streptomycin (Sigma), $5 \times 10^{-5} \mathrm{M} 2$-mercaptoethanol (Sigma) and grown at $37^{\circ} \mathrm{C}$ in a $10 \% \mathrm{CO}_{2}$ humidified environment.

\subsubsection{Preparation of Compounds}

Suspensions of the compounds $\mathbf{1 g}, \mathbf{2 b}, \mathbf{2 m}, \mathbf{3 d}, \mathbf{3} \mathbf{l}$ and sulphadiazine were freshly prepared before the cells were exposed, and diluted $1-500 \mu \mathrm{g} / \mathrm{mL}$ with the culture medium (containing $2.5 \%$ DMSO). Cells treated with 2.5\% DMSO-solvent served as a control in each experiment.

\subsubsection{Cell Viability Assay}

The effects of tested compounds on the viability of mouse fibroblasts L929 cells were evaluated using the MTT [3-(4,5-dimethylthiazol-2-yl)-2,5-diphenyltetrazolium bromide] assay. The MTT assay 
was used according to international standards: ISO 10993-5:2009(E), Biological evaluation of medical devices, Part 5: Tests for in vitro cytotoxicity. L929 cells were placed into 96-well plates at a density of $1.0 \times 10^{4} / 100 \mu \mathrm{L} /$ well in culture medium and allowed to attach and form a confluent monolayer for $24 \mathrm{~h}$ before treatment. Afterwards, culture medium in the plates was replaced by $100 \mu \mathrm{L}$ compounds suspension at concentration of $0-500 \mu \mathrm{g} / \mathrm{mL}$ and the cells were exposed for $24 \mathrm{~h}$. Then, $1 \mathrm{mg} / \mathrm{mL}$ MTT (50 $\mathrm{\mu L} /$ well) was added to each well and incubated at $37{ }^{\circ} \mathrm{C}, 10 \% \mathrm{CO}_{2}$ for $2 \mathrm{~h}$. Mitochondrial dehydrogenases of viable cells reduced the yellowish water-soluble MTT to water-insoluble formazan crystals, which were solubilized with dimethyl sulfoxide (DMSO). The cell culture medium was aspirated cautiously, after which $150 \mu \mathrm{L}$ DMSO was added to each well and mixed thoroughly. Optical density (OD) was read on the ELISA reader (Multiskan EX, Labsystems, Vienna, VA, USA) at $550 \mathrm{~nm}$. The results were expressed as percentage viability compared with the treated $2.5 \%$ DMSO controls. All experiments were performed in triplicate.

\subsection{Antibacterial Assay}

The following microorganisms were used in this study: Staphylococcus aureus (ATCC 25923, ATCC 6538, ATCC 29213, NCTC 4163), Staphylococcus epidermidis ATCC 12228, Bacillus subtilis ATCC 6633, Bacillus cereus ATCC 11778, Micrococcus luteus (ATCC 9341, ATCC 10240), Escherichia coli (ATCC 10538, ATCC 25922, NCTC 8196), Pemphigus vulgaris NCTC 4635, Pseudomonas aeruginosa (ATCC 15442, ATCC 27853, NCTC 6749), and Bordetella bronchiseptica ATCC 4617. Initially, antibacterial activity of thiosemicarbazide derivatives was screened on the basis of growth inhibition zone (giz) utilizing the disc diffusion method, according to the Clinical and Laboratory Standards Institute guidelines [55]. For compounds showing the inhibitory effect on the growth of tested bacteria, monitored as an appearance of giz, the minimal inhibitory concentrations (MICs) were determined using agar dilution method, according to the Clinical and Laboratory Standards Institute guidelines [56]. The minimal inhibitory concentrations (MICs) were defined as the lowest concentration of the compound preventing growth of the tested microorganism. In both methods, recommended Mueller-Hinton II agar medium (Becton Dickinson, Heidelberg, Germany) was used. Solutions containing the tested agents were prepared in methanol or DMSO. Ciprofloxacin was used as control antimicrobial agent.

\subsection{Inhibition of Bacterial Type IIA Topoisomerases}

\subsubsection{Supercoiling Assays}

The assays were performed using S. aureus Gyrase Supercoiling Assay Kits (Inspiralis, Norwich, UK). Briefly, supercoiled pBR322 plasmid DNA $(0.5 \mathrm{mg})$ was incubated with 1 unit of gyrase, in the dedicated supercoiling assay buffer supplied by the manufacturer, in the presence of varying concentrations of the compounds tested. Reactions were carried out at $37{ }^{\circ} \mathrm{C}$ for $1 \mathrm{~h}$ and then terminated by the addition of equal volume of $2 \times$ STOP Buffer (40\% sucrose, $100 \mathrm{mM}$ Tris-Cl $\mathrm{pH} 7.5$, $1 \mathrm{mM}$ EDTA, and $0.5 \mathrm{mg} / \mathrm{mL}$ bromophenol blue) and chloroform/isoamyl alcohol. Samples were vortexed, centrifuged and run through a $15 \mathrm{~cm} 1 \%$ agarose gel in TAE buffer (40 mM Trisacetate, $2 \mathrm{mM}$ EDTA) for $3 \mathrm{~h}$ at $50 \mathrm{~V}$. Gels were stained with ethidium bromide and visualized under UV light. 


\subsubsection{Decatenation Assays}

The assays were performed using $S$. aureus topoisomerase IV decatenation kits (Inspiralis). Interlinked kDNA substrate $(0.5 \mathrm{mg})$ was incubated with 1 unit of topoisomerase IV (Inspiralis), in the dedicated decatenation assay buffer supplied by the manufacturer, in the presence of varying concentrations of the compounds tested. Reactions were carried out at $37{ }^{\circ} \mathrm{C}$ for $1 \mathrm{~h}$ and then terminated by the addition of equal volume of $2 \times$ STOP Buffer ( $40 \%$ sucrose, $100 \mathrm{mM}$ Tris-Cl pH 7.5, $1 \mathrm{mM}$ EDTA, $0.5 \mathrm{mg} / \mathrm{mL}$ bromophenol blue) and chloroform/isoamyl alcohol. Samples were vortexed, centrifuged and run through a $15 \mathrm{~cm} 1 \%$ agarose gel in TAE buffer for $1.5 \mathrm{~h}$ at $80 \mathrm{~V}$. Gels were stained with ethidium bromide and visualized under UV light. The concentrations of the inhibitor that prevented $50 \%$ of the kinetoplast DNA from being converted into decatenated minicircles ( $\mathrm{IC}_{50}$ values) were determined by plotting the results obtained from the densytometric analyses of the gel images using Quantity One software (BioRad, Hercules, CA, USA).

\subsection{Data Analysis}

The results of experiments (3.2. and 3.4.) were shown as a mean arithmetic values from 6-18 repeats (2-6 experiments) and were analyzed for statistical significance with the Statistica PL 5.0 software using the Mann-Whitney U test. During statistical verification, significance levels of * $p<0.05$ were considered.

\subsection{Computational Details}

Conformational search was performed using the Amber force field as implemented in HyperChem 8.0.3. [57] and default convergence criteria. For the most stable conformers population analysis was carried out using the Merz-Kollman scheme [58] at the HF/6-31G theory level with the use of the Gaussian package [59].

\subsection{Docking Studies}

The docking simulations were performed using the FlexX docking module of the LeadIT environment as implemented in the BioSolveITprogram using models of following enzymes: purine nucleoside phosphorylase (PNP; PDB ID: 3MB8 ), adenosine kinase ([EC.2.7.1.20]; PDB ID: 1LII), calcium-dependent protein kinase-1 (TgCDPK1; PDB ID: 4M84), 1-deoxy-D-xylulose-5-phosphate reductoisomerase (DXR; PDB ID: 3AU9), enoyl reductase (TgENR; PDB ID: 2o2s), complexed with their reference ligands. The active sites were defined to include all atoms within $10 \AA$ radius of the native ligands. To validate the docking protocol, ligands co-crystallized with the proteins were initially docked into the crystal structure of the appropriate enzymes; the best conformations obtained were practically identical with the experimental ones. Subsequently, studied compounds were docked using the same docking parameters. The first 100 top ranked docking poses were saved for each docking run. 


\section{Conclusions}

In conclusion, a series of thiosemicarbazides was evaluated in vitro for inhibition of $T$. gondii proliferation and host cell cytotoxicity. All studied compounds displayed significant and reproducible anti-parasitic effects at concentrations that were non-toxic toward the host cells, with experimentally determined $\mathrm{IC}_{50}$ values at least twice (or even fifteen times) higher than that of sulfadiazine. DFT calculations seem to indicate that the activity depends on the bimodal partial negative charge developed on the carbonyl oxygen and another moiety on the same side of the molecule. Since the number of compounds studied here is limited, the above observations can be treated as initial suggestions and will be used as a guide for synthesis of other compounds in further studies.

\section{Supplementary Materials}

Supplementary materials can be accessed at: http://www.mdpi.com/1420-3049/19/7/9926/s1.

\section{Acknowledgments}

The project was partially funded by the National Science Centre (decision number: 2012/05/D/NZ7/02278). We are thankful to Artur Ruszczak_for the technical assistance.

\section{Author Contributions}

Katarzyna Dzitko: Selection of the research theme and the range of studies, the managing of the research project which included the studies described in the manuscript and essential guidance for their correct execution, participation in the discussion of the obtained results, contribution in writing and editing of this manuscript, and correspondence with editorial office. Agata Paneth: Synthesis of studied thiosemicarbazides and participation in the discussion of the results obtained from theoretical calculations. Tomasz Plech: Perform docking simulations. Jakub Pawełczyk: Perform qRT-PCR assay. Joanna Stefańska: Perform antibacterial assay. Paweł Stączek: Perform enzymatic assay. Piotr Paneth: Perform theoretical calculations.

\section{Conflicts of Interest}

The authors declare no conflict of interest.

\section{References}

1. Petersen, E.; Dubey, J.P. Biology of Toxoplasma gondii. In Toxoplasmosis: A Comprehensive Clinical Guide; Joynson, D.H.M., Wreghitt, T., Eds.; Cambridge University Press: Cambridge, UK, 2001; pp. 1-49.

2. Robert-Gangneux, F.; Dardé, M.L. Epidemiology of and diagnostic strategies for toxoplasmosis. Clin. Microbiol. Rev. 2012, 25, 264-296.

3. Contini, C. Clinical and diagnostic management of toxoplasmosis in the immunocompromised patient. Parassitologia 2008, 50, 45-50. 
4. Ambroise-Thomas, P.; Pelloux, H. Toxoplasmosis-congenital and in immunocompromised patients: A parallel. Parasitol. Today 1993, 9, 61-63.

5. Ferreira, M.S.; Borges, A.S. Some aspects of protozoan infections in immunocompromised patients-a review. Mem. Inst. Oswaldo. Cruz. 2002, 97, 443-457.

6. Bosch-Driessen, L.E.; Berendschot, T.T.; Ongkosuwito, J.V.; Rothova, A. Ocular toxoplasmosis: clinical features and prognosis of 154 patients. Ophthalmology 2002, 109, 869-878.

7. Paquet, C.; Yudin, M.H. Toxoplasmosis in pregnancy: Prevention, screening, and treatment. J. Obstet. Gynaecol. Can. 2013, 35, 78-79.

8. Wallon, M.; Kodjikian, L.; Binquet, C.; Garweg, J.; Fleury, J.; Quantin, C.; Peyron, F. Long-term ocular prognosis in 327 children with congenital toxoplasmosis. Pediatrics 2004, 113, 1567-1572.

9. Silveira, C.; Belfort, R.; Muccioli, C.; Holland, G.N.; Victora, C.G.; Horta, B.L.; Fei, Y.; Nussenblatt, R.B. The effect of long-term intermittent trimethoprim/sulfamethoxazole treatment on recurrences of toxoplasmic retinochoroiditis. Am. J. Ophthalmol. 2002, 134, 41-46.

10. Yazici, A.; Ozdal, P.C.; Taskintuna, I.; Kavuncu, S.; Koklu, G. Trimethoprim/Sulfamethoxazole and azithromycin combination therapy for ocular toxoplasmosis. Ocul. Immunol. Inflamm. 2009, 17, 289-291.

11. Dibbern, D.; Montanaro, A. Allergies to sulfonamide antibiotics and sulfur-containing drugs. Ann. Allerg. Asthma Immunol. 2008, 100, 91-101.

12. Kongsaengdao, S.; Samintarapanya, K.; Oranratnachai, K.; Prapakarn, W.; Apichartpiyakul, C. Randomized controlled trial of pyrimethamine plus sulfadiazine versus trimethoprim plus sulfamethoxazole for treatment of toxoplasmic encephalitis in AIDS patients. J. Int. Assoc. Physicians AIDS Care 2008, 7, 11-16.

13. McLeod, R.; Khan, A.R.; Noble, G.A.; Latkany, P.; Jalbrzikowski, J.; Boyer, K. Severe sulfadiazine hypersensitivity in a child with reactivated congenital toxoplasmic chorioretinitis. Pediatr. Infect. Dis. J. 2006, 25, 270-272.

14. Aspinall, T.V.; Joynson, D.H.; Guy, E.; Hyde, J.E.; Sims, P.F. The molecular basis of sulfonamide resistance in Toxoplasma gondii and implications for the clinical management of toxoplasmosis. J. Infect. Dis. 2002, 185, 1637-1643.

15. Remington, J.S.; McLeod, R.; Thulliez, P.; Desmonts, G. Toxoplasmosis. In Infectious Diseases of the Fetus and Newborn Infant, 7th ed.; Remington, J., Klein, J., Eds.; Saunders: Philadelphia, PA, USA, 2011.

16. Degerli, K.; Kilimcioglu, A.A.; Kurt, Ö.; Tamay, T.; Ozbilgin, A. Efficacy of azithromycin in a murine toxoplasmosis model, employing a Toxoplasma gondii strain from Turkey. Acta Trop. 2003, $88,45-50$.

17. Kijlstra, A.; Jongert, E. Toxoplasma-safe meat: Close to reality? Trends Parasitol. 2009, 25, 18-22.

18. Dial, S.; Kezouh, A.; Dascal, A.; Barkun, A.; Suissa, S. Patterns of antibiotic use and risk of hospital admission because of Clostridium difficile infection. CMAJ 2008, 179, 767-772.

19. Megged, O.; Shalit, I.; Yaniv, I.; Stein, J.; Fisher, S.; Levy, I. Breakthrough cerebral toxoplasmosis in a patient receiving atovaquone prophylaxis after a hematopoietic stem cell transplantation. Pediatr. Transplant. 2008, 12, 902-905.

20. Montoya, J.; Remington, J. Management of Toxoplasma gondii infection during pregnancy. Clin. Infect. Dis. 2008, 47, 554-566. 
21. Liesen, A.P.; de Aquino, T.M.; Carvalho, C.S.; Lima, V.T.; de Araújo, J.M.; de Lima, J.G.; de Faria, A.R.; de Melo, E.J.T.; Alves, A.J.; Alves, E.W.; et al. Synthesis and evaluation of anti-Toxoplasma gondii and antimicrobial activities of thiosemicarbazides, 4-thiazolidinones and 1,3,4-thiadiazoles. Eur. J. Med. Chem. 2010, 45, 3685-3691.

22. Siwek, A.; Świderek, K.; Jankowski, S. Problems with molecular mechanics implementations on the example of 4-benzoyl-1-(4-methyl-imidazol-5-yl)-carbonyl-thiosemicarbazide. J. Mol. Model. 2012, 18, 843-849.

23. Plech, T.; Wujec, M.; Siwek, A.; Kosikowska, U.; Malm, A. Synthesis and antimicrobial activity of thiosemicarbazides, s-triazoles and their Mannich bases bearing 3-chlorophenyl moiety. Eur. J. Med. Chem. 2011, 46, 241-248.

24. Derouin, F.; Chastang, C. In vitro effects of folate inhibitors on Toxoplasma gondii. Antimicrob. Agents Chemother. 1989, 33, 1753-1759.

25. Meneceur, P.; Bouldouyre, M.A.; Aubert, D.; Villena, I.; Menotti, J.; Sauvage, V.; Garin, J.F.; Derouin, F. In vitro susceptibility of various genotypic strains of Toxoplasma gondii to pyrimethamine, sulfadiazine, and atovaquone. Antimicrob. Agents Chemother. 2008, 52, 1269-1277.

26. Doliwa, C.; Escotte-Binet, S.; Aubert, D.; Velard, F.; Schmid, A.; Geers, R.; Villena, I. Induction of sulfadiazine resistance in vitro in Toxoplasma gondii. Exp. Parasitol. 2013, 133, 131-136.

27. De Oliveira, T.C.; Silva, D.A.; Rostkowska, C.; Béla, S.R.; Ferro, E.A.; Magalhães, P.M.; Mineo, J.R. Toxoplasma gondii: Effects of Artemisia annua L. on susceptibility to infection in experimental models in vitro and in vivo. Exp. Parasitol. 2009, 122, 233-241.

28. Van der Ven, A.J.; Schoondermark-van de Ven, E.M.; Camps, W.; Melchers, W.J.; Koopmans, P.P.; van der Meer, J.W.; Galama, J.M. Anti-toxoplasma effect of pyrimethamine, trimethoprim and sulphonamides alone and in combination: Implications for therapy. J. Antimicrob. Chemother. 1996, 38, 75-80.

29. Jin, C.; Jung, S.Y.; Kim, S.Y.; Song, H.O.; Park, H. Simple and efficient model systems of screening anti-Toxoplasma drugs in vitro. Expert. Opin. Drug Discov. 2012, 7, 195-205.

30. Alvarez, F.; Ghérardi, A.; Nebois, P.; Sarciron, M.E.; Pétavy, A.F.; Walchshofer, N. Benzimidazole-4,7-diones as inhibitors of protozoal (Toxoplasma gondii) purine nucleoside phosphorylase. Bioorg. Med. Chem. Lett. 2002, 12, 977-979.

31. Kim, Y.A.; Rawal, R.K.; Yoo, J.; Sharon, A.; Jha, A.K.; Chu, C.K.; Rais, R.H.; Al Safarjalani, O.N.; Naguib, F.N.M.; Kouni, M.H. Structure-activity relationships of carbocyclic 6-benzylthioinosine analogues as subversive substrates of Toxoplasma gondii adenosine kinase. Bioorg. Med. Chem. 2010, 18, 3403-3412.

32. Rosowsky, A.; Chen, H.; Fua, H.; Queener, S.F. Synthesis of new 2,4-diaminopyrido[2,3d]pyrimidine and 2,4-diaminopyrrolo[2,3-d]pyrimidine inhibitors of pneumocystis carinii, Toxoplasma gondii, and Mycobacterium avium dihydrofolate reductase. Bioorg. Med. Chem. 2003, 11, 59-67.

33. Rosowsky, A.; Forsch, R.A.; Queener, S.F. 2,4-Diaminopyrido[3,2-d]pyrimidine inhibitors of dihydrofolate reductase from Pneumocystis carinii and Toxoplasma gondii. J. Med. Chem. 1995, $38,2615-2620$. 
34. Ojo, K.K.; Larson, E.T.; Keyloun, K.R.; Castaneda, L.J.; de Rocher, A.E.; Inampudi, K.K.; Kim, J.E.; Arakaki, T.L.; Murphy, R.C.; Zhang, L.; et al. Toxoplasma gondii calcium-dependent protein kinase 1 is a target for selective kinase inhibitors. Nat. Struct. Mol. Biol. 2010, 17, 602-607.

35. Murphy, R.C.; Ojo, K.K.; Larson, E.T.; Castellanos-Gonzalez, A.; Perera, B.G.K.; Keyloun, K.R.; Kim, J.E.; Bhandari, J.G.; Muller, N.R.; Verlinde, C.L.M.J.; et al. Discovery of potent and selective inhibitors of calcium-dependent protein kinase 1 (CDPK1) from C. parvum and T. gondii. ACS Med. Chem. Lett. 2010, 1, 331-335.

36. Sugi, T.; Kato, K.; Kobayashi, K.; Watanabe, S.; Kurokawa, H.; Gong, H.; Pandey, K.; Takemae, H.; Akashi, H. Use of the kinase inhibitor analog 1NM-PP1 reveals a role for Toxoplasma gondii CDPK1 in the invasion step. Eukaryot. Cell 2010, 9, 667-670.

37. Zhang, Z.; Ojo, K.K.; Johnson, S.M.; Larson, E.T.; He, P.; Geiger, J.A.; Castellanos-Gonzalez, A.; White, A.C., Jr.; Parsons, M.; Merritt, E.A.; et al. Benzoylbenzimidazole-based selective inhibitors targeting Cryptosporidium parvum and Toxoplasma gondii calcium-dependent protein kinase-1. Bioorg. Med. Chem. Lett. 2012, 22, 5264-5267.

38. Cai, G.; Deng, L.; Xue, J.; Moreno, S.N.J.; Striepen, B.; Song, Y. Expression, characterization and inhibition of Toxoplasma gondii 1-deoxy-D-xylulose-5-phosphate reductoisomerase. Bioorg. Med. Chem. Lett. 2013, 23, 2158-2161.

39. Hunter, W.N. The non-mevalonate pathway of isoprenoid precursor biosynthesis. J. Biol. Chem. 2007, 282, 21573-21577.

40. Singh, N.; Cheve, G.; Avery, M.A.; McCurdy, C.R. Targeting the methyl erythritol phosphate (MEP) pathway for novel antimalarial, antibacterial and herbicidal drug discovery: Inhibition of 1-deoxy-D-xylulose-5-phosphate reductoisomerase (DXR) enzyme. Curr. Pharm. Des. 2007, 13, 1161-1177.

41. Cheng, G.; Muench, S.P.; Zhou, Y.; Afanador, G.A.; Mui, E.J.; Fomovska, A.; Lai, B.S.; Prigge, S.T.; Woods, S.; Roberts, C.W; et al. Design, synthesis, and biological activity of diaryl ether inhibitors of Toxoplasma gondii enoyl reductase. Bioorg. Med. Chem. Lett. 2013, 23, 2035-2043.

42. Kramer, B.; Rarey, M.; Lengauer, T. Evaluation of the FLEXX incremental construction algorithm for protein-ligand docking. Proteins 1999, 37, 228-241.

43. LeadIT, version 2.1.0; BioSolveIT GmbH: St. Augustin, Germany, 2012.

44. Siwek, A.; Stączek, P.; Stefańska, J. Synthesis and structure-activity relationship studies of 4-arylthiosemicarbazides as topoisomerase IV inhibitors with Gram-positive antibacterial activity. Search for molecular basis of antibacterial activity of thiosemicarbazides. Eur. J. Med. Chem. 2011, 46, 5717-5726.

45. Siwek, A.; Stączek, P.; Wujec, M.; Stefańska, J.; Kosikowska, U.; Malm, A.; Jankowski, S.; Paneth, P. Biological and docking studies of topoisomerase IV inhibition by thiosemicarbazides. J. Mol. Model. 2011, 17, 2297-2303.

46. Andersonm, V.E.; Gootz, T.D.; Osheroff, N. Topoisomerase IV Catalysis and the Mechanism of Quinolone Action. J. Biol. Chem. 1998, 273, 17879-17885.

47. Nath, T.G.S.; Husain, S.; Srinivasan, V.R. Synthesis and reactivity of 4,5-disubstituted 3-chloro1,2,4-triazoles and their methylsulfonyl analogs. Indian J. Chem. Sec. B 1977, 15B, 341-346. 
48. Siwek, A.; Stefańska, J.; Dzitko, K.; Ruszczak, A. Antifungal effect of 4-arylthiosemicarbazides against Candida species. Search for molecular basis of antifungal activity of thiosemicarbazide derivatives. J. Mol. Model. 2012, 18, 4159-4170.

49. Chen, H.-L.; Guo, Z.-F.; Lu, Z.-L. Controlling ion-sensing specificity of $N$-amidothioureas: From anion-selective sensors to highly $\mathrm{Zn}^{2+}$-selective sensors by tuning electronic effects. Org. Lett. 2012, 14, 5070-5073.

50. Goldfarb, D.S. Method Using Lifespan-Altering Compounds For Altering The Lifespan Of Eukaryotic Organisms, and Screening for Such Compounds. U.S. Patent US20090163545 A1, 25 June 2009.

51. Siwek, A.; Wujec, M.; Dobosz, M.; Jagiello-Wojtowicz, E.; Kleinrok, A.; Chodkowska, A.; Paneth, P. Chemical and pharmacological properties of 3-(thiophen-2-yl)-4-substituted- $\Delta^{2}-1,2,4-$ triazoline-5-thiones. Phosphorus Sulfur 2008, 183, 2669-2677.

52. Siwek, A.; Wujec, M.; Stefanska, J.; Paneth, P. Antimicrobial properties of 4-aryl-3-(2-methylfuran-3-yl)- $\Delta^{2}$-1,2,4-triazoline-5-thiones. Phosphorus Sulfur 2009, 184, 3149-3159.

53. Burg, J.L.; Grover, C.M.; Pouletty, P.; Boothroyd, J.C. Direct and sensitive detection of a pathogenic protozoan, Toxoplasma gondii, by polymerase chain reaction. J. Clin. Microbiol. 1989, 27, 1787-1792.

54. Wahab, T.; Edvinsson, B.; Palm, D.; Lindh, J. Comparison of the AF146527 and B1 repeated elements, two real-time PCR targets used for detection of Toxoplasma gondii. J. Clin. Microbiol. 2010, 48, 591-592.

55. Clinical and Laboratory Standards Institute. Performance Standards for Antimicrobial disc Susceptibility Tests, Approved Standard M2-A9; Clinical and Laboratory Standards Institute: Wayne, PA, USA, 2006.

56. Clinical and Laboratory Standards Institute. Methods for Dilution Antimicrobial Susceptibility Tests for Bacteria that Grow Aerobically, Approved Standard M7-A7; Clinical and Laboratory Standards Institute: Wayne, PA, USA, 2006.

57. Hyperchem, version 8.0.3; HyperCube Inc.: Gainsville, FL, USA, 2007.

58. Singh, U.C.; Kollman, P.A. An approach to computing electrostatic charges for molecules. J. Comp. Chem. 1984, 5, 129-145.

59. Frisch, M.J. Gaussian 09, revision A.02. Gaussian Inc.: Wallingford, CT, USA, 2009.

Sample Availability: Samples of the tested compounds are available from the authors.

(C) 2014 by the authors; licensee MDPI, Basel, Switzerland. This article is an open access article distributed under the terms and conditions of the Creative Commons Attribution license (http://creativecommons.org/licenses/by/3.0/). 